\title{
Blood group incompatibility and accelerated homograft fibrocalcifications
}

\author{
Jan T. Christenson, MD, FETCS \\ Dominique Vala, $\mathrm{MD}^{\mathrm{a}}$ \\ Jorge Sierra, MD \\ Maurice Beghetti, MD \\ Afksendiyos Kalangos, MD, FETCS ${ }^{a}$
}

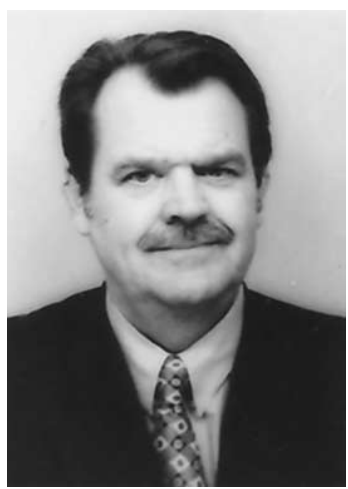

Dr Christenson
From the Clinic for Cardiovascular Surgery $^{\mathrm{a}}$ and Department of Pediatric Cardiology, ${ }^{\mathrm{b}}$ University Hospital of Geneva, Geneva, Switzerland.

Read at the Eighty-third Annual Meeting of The American Association for Thoracic Surgery, Boston, Mass, May 4-7, 2003.

Received for publication April 14, 2003; revisions requested June 26, 2003; accepted for publication July 22, 2003.

Address for reprints: Dr Jan T. Christenson, MA, MD, PD, FETCS, Clinic for Cardiovascular Surgery, University Hospital of Geneva, 24 rue Micheli-du-Crest, $\mathrm{CH}-1211$ Geneva 14, Switzerland (E-mail: jan.christenson@hcuge.ch).

J Thorac Cardiovasc Surg 2004;127:242-50 $0022-5223 / \$ 30.00$

Copyright $\odot 2004$ by The American Association for Thoracic Surgery

doi:10.1016/j.jtcvs.2003.07.047
Objective: Cryopreserved valved homograft has become the conduit of choice for right ventricular outflow tract reconstruction in pediatric cardiac surgery. Aortic homografts have been frequently used in pulmonary position, but accelerated aortic homograft fibrocalcification may occur. Blood group incompatibility between receiver and homograft donor may play a central role in this context.

Methods: Between 1993 and 2000, 59 children (mean age $6.4 \pm 4.4$ years) received cryopreserved valved homografts for right ventricular outflow tract reconstruction and were followed from 2 to 10 years clinically, with echocardiography and chest radiography for detection of development of homograft calcifications. Seventeen patients were 3 years or younger. Fifty aortic $(85 \%)$ and 9 pulmonary homografts were all used in pulmonary position. Thirty-three patients (56\%) had the same blood group (ABO) as the homograft donor (iso group), and 26 were blood groupincompatible (non-iso group).

Results: No deaths occurred during follow-up. Six patients (10.2\%) required homograft replacement because of severe fibrocalcifications, and another 3 showed moderate homograft calcifications $(5.1 \%)$ at last examination. Freedom from moderate to severe homograft calcification at 8 years (Kaplan-Meier) was $95.2 \%$ for the iso group and $72.9 \%$ for the non-iso group $(P<.0001)$. Homograft calcifications occurred within 2 years of implantation in $6 / 9$ patients $(67 \%)$ in the non-iso group.

Conclusions: Blood group incompatibility between receiver and homograft donor seems to play an important role in the development of accelerated fibrocalcifications in cryopreserved homografts, particularly in the very young (3 years old or younger). Blood group compatibility should therefore be respected to avoid accelerated homograft fibrocalcifications.

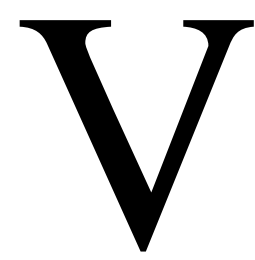

alved homografts, introduced in the $1960 \mathrm{~s},{ }^{1}$ have become the most commonly used valved conduit for reconstruction of the right ventricular outflow tract (RVOT). ${ }^{2,3}$ Advantages of homografts, such as ease of handling and improved hemostasis, have been major contributing factors in its widespread use. ${ }^{4}$ Early results with cryopreserved homografts have been good. ${ }^{5,6}$ Frequently cryopreserved valved aortic homografts are used in pulmonary position due to difficulties in obtaining pulmonary homografts, but accelerated aortic homograft fibrocalcifications have been described..$^{7-9}$ The reason for this phenomenon is not entirely understood. It has been suggested that aortic cryopreserved homografts are more prone to calcifications than pulmonary homografts, possibly due to a higher content of elastic tissue and calcium in the aortic wall. ${ }^{7}$ Moreover, early cryopreservation may provide viable endothelial cells and perhaps also viable fibroblasts, thus contributing to a greater proportion of antigenically active cells, which could lead to 
TABLE 1. Primary diagnosis for 59 pediatric patients where cryopreserved valved homografts were used for RVOT reconstruction

\begin{tabular}{lr}
\hline Primary diagnosis & No. \\
\hline Tetralogy of Fallot & 25 \\
Pulmonary stenosis or atresia & 11 \\
Complex transposition & 9 \\
Pulmonary atresia and ventricular septal defect & 8 \\
Truncus arteriosus & 6 \\
Total & 59
\end{tabular}

a more intense host response. ${ }^{10-13}$ This increased immunogenicity of the graft could perhaps be an important contributing factor for accelerated fibrocalcifications, particularly in very young patients. This study was undertaken to evaluate the impact of blood group incompatibility on cryopreserved homograft calcification when used for reconstruction of the RVOT in a pediatric population.

\section{Methods}

From June 1993 and December 2000, 59 pediatric patients (32 boys and 27 girls) had cryopreserved valved homografts implanted for RVOT reconstruction. The mean age was $6.4 \pm 4.4$ years, ranging from 1 month to 14 years of age. Seventeen patients (29\%) were 3 years old or younger at the time of surgery. Primary diagnosis of their congenital lesions is listed in Table 1 . Thirtyeight patients $(64 \%)$ had undergone at least 1 earlier cardiac intervention (Table 2). Thirty-three patients (56\%) had the same blood group (ABO) as the homograft donor (iso group), and in 26 cases there was blood group incompatibility (non-iso group). All patients in the iso group received homografts within their own blood group. Potentially compatible homografts were not used in this series. Fifty aortic valved homografts (85\%) and 9 pulmonary homografts were used, all in pulmonary position.

\section{Homograft Procurement and Preparation}

Valved cryopreserved homografts were obtained from 2 sources, the European Homograft Bank (Brussels Military Hospital, Belgium) and CryoLife Inc (Marietta, Ga). The techniques for preparation of antibiotic-sterilized cryopreserved homografts and storage in liquid nitrogen have been described earlier. ${ }^{14}$

\section{Surgical Technique}

Two surgeons performed all operations. The operation was performed through a median sternotomy and standard cardiopulmonary bypass techniques were applied. During moderate hypothermia $\left(28^{\circ} \mathrm{C}\right.$ to $\left.32^{\circ} \mathrm{C}\right)$ and following crossclamping, myocardial protection was ensured by crystalloid cold cardioplegic solution repeated every 30 minutes. A longitudinal incision was made through the right ventricle outflow tract and extended up to the pulmonary bifurcation and then into both pulmonary branches. The size of the homograft was determined and was always larger than the minimum acceptable pulmonary annulus diameter as described by Pacifico and associates. ${ }^{15}$ The diameter of the homografts in this series ranged from 13 to $26 \mathrm{~mm}$ (mean diameter $20 \mathrm{~mm}$ ).
TABLE 2. Previous cardiac interventions in 38 pediatric patients receiving cryopreserved valve homografts

Previous surgical procedure

No.

Modified Blalock-Taussig shunt

11

Tetralogy of Fallot repair

Ventricular septal defect repair

RVOT annular patch

Rastelli repair

Brock operation

Waterstone procedure

Pulmonary valvotomy

Total

10

5

4

3

2

1

RVOT, Right ventricular outflow tract.

Homografts were thawed and trimmed in standard fashion after intraoperative assessment of the anatomy. A cryopreserved valved homograft was then inserted between the extended pulmonary bifurcation and the right ventricle at the level of the crista supraventricularis. The distal anastomoses were performed first. In some patients bovine or autologous pericardium was used to enlarge the pulmonary arteries or to provide continuity between the pulmonary arteries. The proximal anastomoses were made to vertical infundibulotomies. In addition, a patch of bovine or autologous pericardium was inserted as a hood to cover the enlarged infundibulotomy. No prosthetic material was used. Associated procedures were ventricular septal defect closure $(n=20)$, atrial septal defect closure $(n=5)$, patch plasty of pulmonary artery branches $(n=13)$, closure of patent foramen ovale $(n=4)$, tricuspid valve repair $(\mathrm{n}=3)$, and tricuspid valve replacement with mitral homograft $(n=1)$.

\section{Follow-up}

All surviving patients were examined in the immediate postoperative period and reexamined with serial transthoracic echocardiography and chest radiography every 6 months, until December 2002. The mean follow-up was 48 months, ranging from 26 to 126 months, with a median follow-up of 39 months. Stenosis was assessed by measurement of peak velocity through the valve with continuous-wave Doppler technique. Pulmonary regurgitation was examined by evaluation of regurgitated jet with pulsed color-flow Doppler.

\section{Statistical Analysis}

Data are presented as the mean \pm standard deviation. Continuous variables were analyzed with Student $t$ test and categorical variables using $\chi^{2}$ test. Actuarial estimates were calculated using the Kaplan-Meier method.

\section{Results}

There was no hospital mortality and no mortality during follow-up. During follow-up 9 patients showed moderate to severe homograft fibrocalcifications generating either a significant pulmonary stenosis or valvular dysfunction or a combination of both. Oversizing the homograft was achieved in $90 \%$ of the patients, with no difference between the groups. Sex and age distribution was also without group 


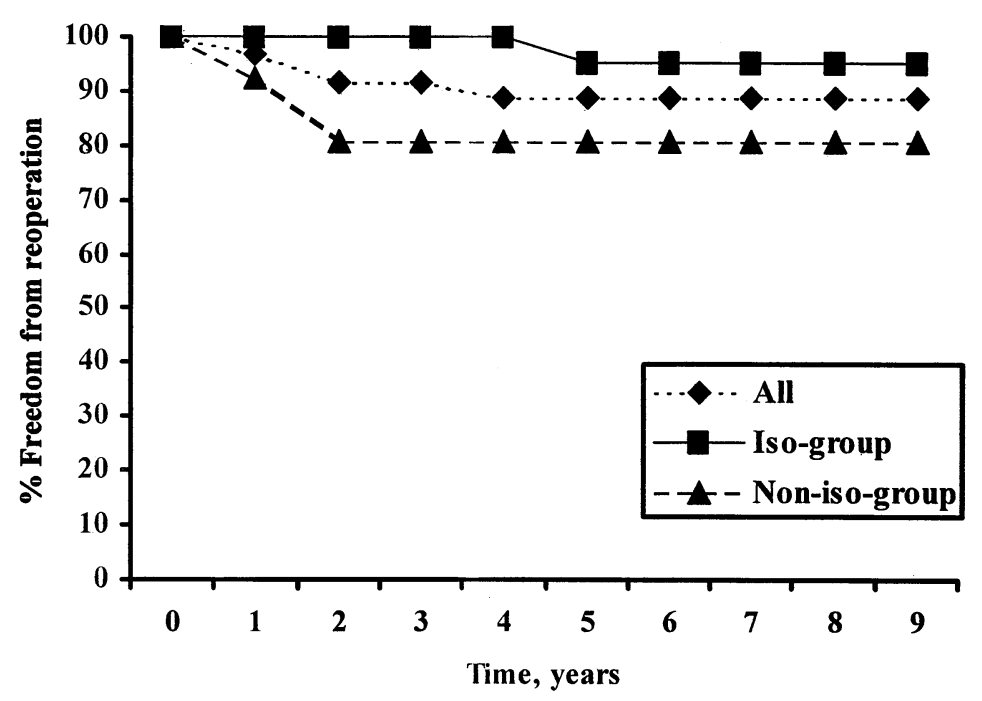

Patients at risk

$\begin{array}{lrrrrrrrrrr}\text { All } & \mathbf{5 9} & \mathbf{5 9} & \mathbf{5 7} & \mathbf{4 5} & \mathbf{4 3} & \mathbf{3 3} & \mathbf{3 0} & \mathbf{2 3} & \mathbf{1 9} & \mathbf{7} \\ \text { Iso-group } & \mathbf{3 3} & \mathbf{3 3} & \mathbf{2 9} & \mathbf{2 7} & \mathbf{2 1} & \mathbf{1 9} & \mathbf{1 7} & \mathbf{1 3} & \mathbf{8} & \mathbf{3} \\ \text { Non-iso group } & \mathbf{2 6} & \mathbf{2 6} & \mathbf{2 4} & \mathbf{2 1} & \mathbf{1 6} & \mathbf{1 2} & \mathbf{1 1} & \mathbf{6} & \mathbf{6} & \mathbf{4}\end{array}$

Figure 1. Overall actuarial freedom from reoperation in 59 pediatric patients undergoing reconstruction of the right ventricular outflow tract with cryopreserved homograft and separated into blood group-compatible $(\mathbf{n}=33)$ and blood group-incompatible $(\mathbf{n}=26$ ) grafts.

difference. Mean gradient right ventricle to pulmonary artery was $15.5 \pm 13.2 \mathrm{~mm} \mathrm{Hg}$, ranging from 0 to $49 \mathrm{~mm} \mathrm{Hg}$, at 3 months after homograft implantation. None of the patients had a gradient greater than $49 \mathrm{~mm} \mathrm{Hg}$. Homograft calcifications occurred more frequently in the non-iso group $(26.9 \% ; 7 / 26)$, than in the iso group $(6.1 \% ; 2 / 33 ; P=.051)$.

\section{Reoperations}

Six of the patients with homograft calcifications and valvular dysfunction (10.2\%) required homograft replacements. Two patients underwent reoperation within the first postoperative year and 3 had reoperation during the second year of homograft implantation. All these 5 patients belonged to the non-iso group. One patient underwent reoperation 5 years after the initial homograft implantation and this patient belonged to the iso group. The overall actuarial freedom from reoperation was $88.8 \%$ at 8 years, with a notable difference between the iso group $(95.2 \%)$ and the non-iso group $(80.8 \% ; 70 \%$ confidence interval, $91 \%$ to $99 \%$ and $72 \%$ to $89 \%$, respectively; Figure 1).

Moderate fibrocalcifications without valvular dysfunction was observed in another 3 patients $(5.1 \%)$, none of them severe enough to require reoperation. These patients continue to be under close surveillance. The overall actuarial freedom from moderate to severe fibrocalcifications (also including reoperations for homograft dysfunction) was
$85.5 \%$ at 5 years and $85.5 \%$ at 8 years, respectively, again with a remarkable difference between the iso group (95.2\% and $95.2 \%)$ and the non-iso group (72.9\% and $72.9 \% ; 70 \%$ confidence interval at 8 years, $91 \%$ to $99 \%$ and $65 \%$ to $81 \%$, respectively; Figure 2).

It should be noted that moderate to severe homograft calcifications with or without homograft dysfunction were diagnosed within 2 years of homograft implantation in as many as 6 of the 9 patients (67\%), all in the non-iso group. Later appearance of homograft fibrocalcifications was equally distributed between the groups.

Homograft valvular regurgitation was seen in 3 patients during follow-up. One patient was diagnosed 6 years after homograft implantation (non-iso group), and 2 patients were diagnosed 7 years after homograft implantation (1 from each group). The regurgitation was minimal to moderate and reoperation has so far not been necessary.

Overall actuarial freedom from homograft dysfunction (moderate to severe fibrocalcifications as well as homograft valve regurgitation) was $83.8 \%$ at 5 years and $67.2 \%$ at 8 years. When blood group compatibility was respected (iso group), freedom from homograft dysfunction was $95.2 \%$ at 5 years (70\% confidence interval, $92 \%$ to $98 \%$ ) and $83.9 \%$ at 8 years (70\% confidence interval, $64 \%$ to $80 \%)$, which should be compared with $71.8 \%$ (70\% confidence interval, $67 \%$ to $77 \%$ ) and $53.2 \%$, respectively, if there was blood 


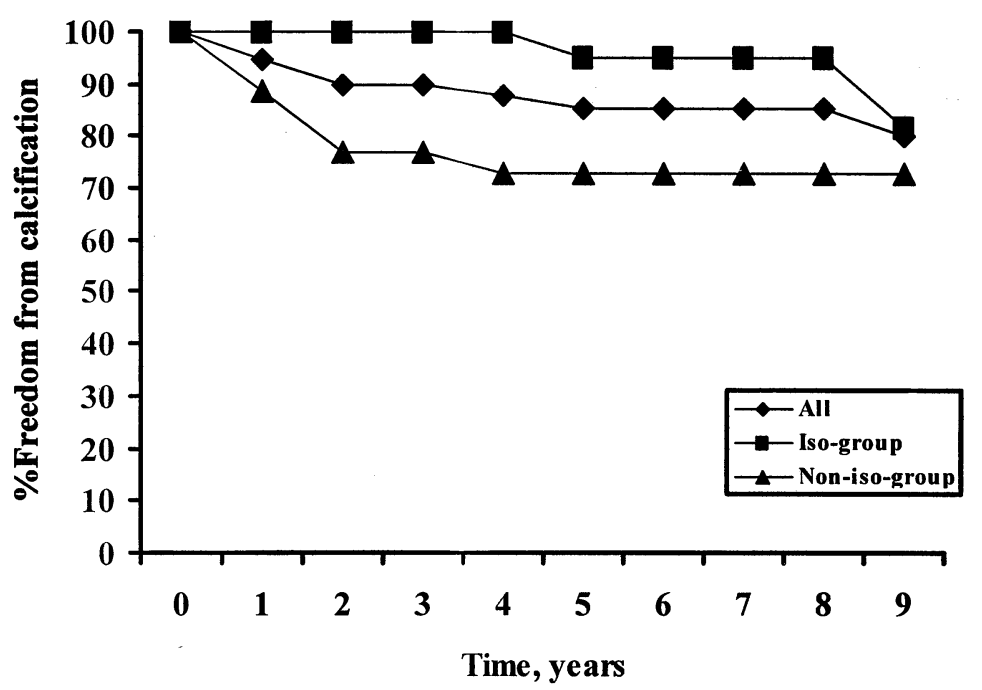

Patients at risk

$\begin{array}{lllllllllll}\text { All } & \mathbf{5 9} & \mathbf{5 6} & \mathbf{4 9} & \mathbf{4 6} & \mathbf{3 8} & \mathbf{3 4} & \mathbf{3 0} & \mathbf{2 6} & \mathbf{1 6} & \mathbf{7} \\ \text { Iso-group } & \mathbf{3 3} & \mathbf{3 3} & \mathbf{2 9} & \mathbf{2 7} & \mathbf{2 1} & \mathbf{1 8} & \mathbf{1 6} & \mathbf{1 2} & \mathbf{7} & \mathbf{3} \\ \text { Non-iso-group } & \mathbf{2 6} & \mathbf{2 3} & \mathbf{2 0} & \mathbf{1 9} & \mathbf{1 7} & \mathbf{1 6} & \mathbf{1 4} & \mathbf{1 4} & \mathbf{9} & \mathbf{4}\end{array}$

Figure 2. Overall actuarial freedom from moderate to severe fibrocalcifications in $\mathbf{5 9}$ pediatric patients undergoing reconstruction of the right ventricular outflow tract with cryopreserved homograft and separated into blood group-compatible $(n=33)$ and blood group-incompatible $(n=26)$ grafts.

group incompatibility between homograft donor and homograft recipient (non-iso group; Figure 3).

\section{Impact of Age, Blood Group Incompatibility, and Homograft Fibrocalcifications}

Children 3 years old or younger in this series encountered fibrocalcifications markedly more frequent than patients older than 3 years, $29.4 \%$ (5/17) versus 9.5\% (4/42). Even though this difference did not reach statistical significance $(P=.059)$, a clear trend is apparent. All patients who developed fibrocalcifications in the young age group in the early period (within 2 years) after homograft implantation had blood group incompatibility between homograft donor and recipient (non-iso group; 55.6\%, 5/9 patients), and no fibrocalcifications were observed in the young when blood group compatibility was observed (iso group). This difference between iso group and non-iso group was not encountered in patients older than 3 years (Table 3 ).

Even with different protocols for homograft harvest and preparation at the 2 homograft sources, no difference in outcome was found either within or across ABO compatibility (Table 3 ).

Because of the small number of pulmonary homografts used in this series, a meaningful comparison between pulmonary and aortic homografts in RVOT reconstruction could not be done, even though there was seemingly no major difference in outcome, as long as blood group compatibility when using aortic homografts was observed.

\section{Discussion}

Homografts have been used as extracardiac conduit between the right ventricle and the pulmonary arteries in various congenital cardiac malformations, such as complex tetralogy of Fallot, truncus arteriosus,${ }^{16}$ pulmonary atresia, ${ }^{1}$ and transposition of the great arteries with ventricular septal defect and pulmonary artery stenosis, ${ }^{17}$ as well as other forms of congenital cardiac disease. ${ }^{18}$ However, initial results after homografts resulted in a high incidence of homograft calcifications and subsequent graft failure. Changes in homograft procurement techniques and utilization of fresh homografts sterilized with antibiotics and preserved by freezing led to improved results, which sparked a renewed interest for the use of homografts in RVOT reconstruction in children. ${ }^{19}$ Today the cryopreserved valved homograft is the most commonly used conduit for RVOT reconstruction. Excellent patient survival after RVOT reconstruction using cryopreserved homografts has been reported, ${ }^{2,11,20,21}$ which also was demonstrated in the present series. However, homograft calcifications and degeneration still remain a problem, and the underlying cause for this progressive development of conduit degeneration is still under discussion. Echocardiography has been shown to be a 


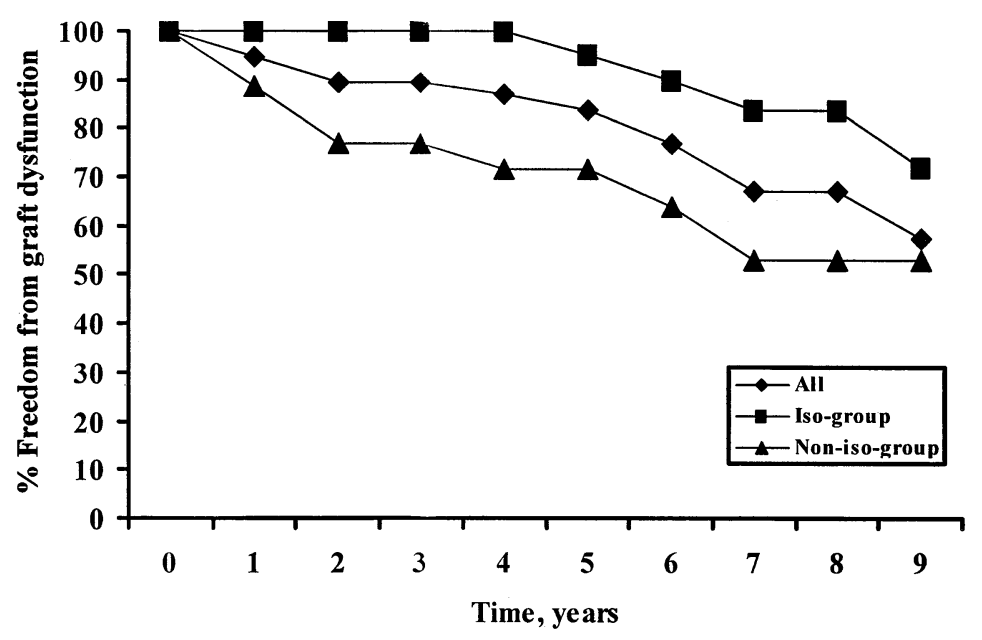

$\begin{array}{lrrrrrrrrrr}\text { Patients at risk } & & & & & & & & & \\ \text { All } & \mathbf{5 9} & \mathbf{5 9} & \mathbf{5 2} & \mathbf{4 6} & \mathbf{3 6} & \mathbf{2 8} & \mathbf{2 4} & \mathbf{1 6} & \mathbf{1 2} & \mathbf{7} \\ \text { Is0-group } & \mathbf{3 3} & \mathbf{3 3} & \mathbf{2 9} & \mathbf{2 7} & \mathbf{2 1} & \mathbf{1 8} & \mathbf{1 5} & \mathbf{1 0} & \mathbf{7} & \mathbf{3} \\ \text { Non-iso-group } & \mathbf{2 6} & \mathbf{2 6} & \mathbf{2 3} & \mathbf{1 9} & \mathbf{1 5} & \mathbf{1 0} & \mathbf{9} & \mathbf{6} & \mathbf{5} & \mathbf{4}\end{array}$

Figure 3. Overall actuarial freedom from homograft dysfunction (including fibrocalcifications and homograft valvular regurgitation) in $\mathbf{5 9}$ pediatric patients undergoing reconstruction of the right ventricular outflow tract with cryopreserved homograft and separated into blood group-compatible $(n=33)$ and blood group-incompatible $(n=$ 26) grafts.

TABLE 3. Cryopreserved valved homograft fibrocalcification for RVOT reconstruction in a pediatric population, separated into 2 age groups $(3$ years or older and older than 3 years of age) in relation to blood group compatibility between homograft donor and recipient (iso group) versus blood group incompatibility (non-iso group) and impact of homograft source

\begin{tabular}{lcc}
\hline & \multicolumn{2}{c}{ Fibrocalcifications/No. of patients } \\
\cline { 2 - 3 } Age at implantation & $\begin{array}{c}\text { Iso group, } \\
\text { no. (\%) }\end{array}$ & $\begin{array}{c}\text { Non-iso group, } \\
\text { no. (\%) }\end{array}$ \\
\hline 3 years or younger, $\mathrm{n}=17$ & $0 / 8(0.0)$ & $5 / 9(55.6)$ \\
$\quad$ Homograft source & & \\
$\quad$ CryoLife & $0 / 4(0.0)$ & $2 / 4(50.0)$ \\
$\quad$ Brussels & $0 / 4(0.0)$ & $3 / 5(60.0)$ \\
Older than 3 years, $\mathrm{n}=42$ & $2 / 25(8.0)$ & $2 / 17(11.8)$ \\
$\quad$ Homograft source & & \\
$\quad$ CryoLife & $1 / 12(8.3)$ & $1 / 8(12.5)$ \\
$\quad$ Brussels & $1 / 13(7.7)$ & $1 / 9(11.1)$ \\
Total, $\mathrm{n}=59$ & $2 / 33(6.1)$ & $7 / 26(26.9)$ \\
$\quad$ Homograft source & & \\
$\quad$ CryoLife & $1 / 16(6.3)$ & $3 / 12(25.0)$ \\
$\quad$ Brussels & $1 / 17(5.9)$ & $4 / 14(28.6)$ \\
\hline
\end{tabular}

RVOT, Right ventricular outflow tract.

reliable method of assessing homograft function during follow-up, ${ }^{6,11}$ and serial echocardiographic follow-up examinations for detection of homograft valvular failure was consequently employed in the present series.
Several factors have been suggested as cause for homograft calcification and subsequent graft failure. Small size of the homograft in comparison to the patient's body surface area is 1 such factor. ${ }^{11,22,23}$ Others risk factors for homograft degeneration, such as young age of the homograft recipient and the use of Dacron conduit extension, have been demonstrated. ${ }^{4,5,11}$ The use of aortic valved homografts in the RVOT has been suggested to be a risk factor in some studies ${ }^{2}$ but not in others. ${ }^{3,6}$ Although the vast majority of the patients in our series $(85 \%)$ received aortic homografts, good long-term freedom from graft dysfunction was still obtained, which is consistent with several previous reports. ${ }^{3,6}$

Earlier suggestions regarding the practice of oversizing valves to allow for growth ${ }^{11,15}$ was strictly observed for all patients in our series.

The majority of our patients had as primary diagnosis tetralogy of Fallot and only few with transposition of the great arteries, which could explain the good results achieved in our series. This is consistent with data recently reported by Dearani and associates, ${ }^{24}$ who showed that the best results were obtained for patients with diagnosis of tetralogy of Fallot and the worst results followed surgery for transposition of the great arteries. Similar findings have also been reported by others. ${ }^{2}$

An additional participating risk factor for homograft failure is related to the material used as a hood to cover the enlarged right ventriculotomy, as well as for patch enlarge- 
ment of the pulmonary arteries. ${ }^{2,3,11,25} \mathrm{We}$ consistently use an autologous or bovine pericardium for these patches, which may have contributed to the good outcome reported in our series.

In addition, solid evidence have recently been presented in the literature that not only nonimmunological factors but also an immunological response plays a major role in subsequent homograft dysfunction. ${ }^{25}$ It has been shown that cryopreservation results in preservation of endothelial cells and fibroblasts. ${ }^{13,25}$ Viable endothelial cells and fibroblasts are thought to provide the strongest antigenicity. ${ }^{13}$ Baskett and coworkers ${ }^{11}$ recently presented data showing that the length of time the homograft is sterilized before freezing is an independent risk factor if the time from retrieval to preservation was shorter than 24 hours. The homografts used in the present series all had time from retrieval to preservation of no more than 72 hours.

Accelerated homograft dysfunction in very young patients has been suggested earlier. ${ }^{2,3}$ This accelerated homograft fibrocalcification is not yet fully understood, even though there is some evidence that it could be the related to a host immunological response. ${ }^{8,13,25}$ Both blood group incompatibility (ABO) and human leukocyte antigens (HLA) incompatibility are factors involved in the immunological response that could affect implanted cryopreserved homografts. Blood group ( $\mathrm{ABO}$ ) incompatibility between homograft donor and recipient as a possible major risk factor resulting in an important immunological response has been debated extensively. ${ }^{10,24,25}$ Even though several large series have failed to identify blood group incompatibility as an independent risk factor, ${ }^{26}$ Baskett and associates ${ }^{11}$ in a recent study have demonstrated that blood group incompatibility indeed was a significant independent predictor of homograft failure in multivariate analysis. Our data strongly support the importance of blood group compatibility as an important risk factor for accelerated homograft fibrocalcification, particularly in the very young patients when cryopreserved aortic valved homografts were used for RVOT reconstruction. A distinct relationship between young age at homograft implantation and accelerated, early homograft dysfunction was clearly demonstrated in our data when there was blood group incompatibility, which is consistent with data reported by others. ${ }^{2,26}$

It has been suggested that homograft failure in very young children may result from immune response or rejection. ${ }^{6,8,11,25}$ Hawkins and associates ${ }^{27}$ have recently shown that cryopreserved homografts in children induce a marked response involving both class I and II anti-HLA antibodies. Interestingly, this immune response occurs very early, within 3 months of graft implantation. ${ }^{27}$ Immunosuppression of the recipient to diminish the immunological response has been suggested by some ${ }^{10}$ but opposed by others. ${ }^{28}$ However, in a recent prospective randomized trial
Shaddy and coworkers ${ }^{29}$ were not able to show any reduction in antibody response when azathioprine was administrated, and immunosuppression therapy is therefore not presently recommended. Perhaps strict observance of blood group compatibility between homograft donor and the very young graft recipient could be one way to diminish the risk of accelerated homograft fibrocalcifications as suggested by our data.

Factors contributing to late homograft failure such as young age at surgery, late immunological response, and geometric distortion together with small graft size have been pointed out earlier. Loss of valvular leaflet extensibility over time has been suggested to result in increasing valvular regurgitation. ${ }^{30}$ In a recent study Baskett and associates ${ }^{11}$ suggested that long-term homograft dysfunction might result from decreased graft viability, early immunological rejection, or a combination of the two in conjunction with subtle geometric distortion.

\section{Conclusion}

Even though homograft immunogenicity has been demonstrated to be retained despite the attenuation of endothelial viability, it is apparent that the precise nature of homograft valve viability and immunogenicity is not yet fully understood. Although immunological factors do not exclusively explain valved homograft failure, they cannot be ignored as important factors triggering early and accelerated homograft failure, particularly in the very young children. Previous studies as well as data presented in this series have indicated that early homograft failure is more in keeping with rejection than the inevitable tissue degeneration seen in later failures.

In the present series a markedly higher incidence of early homograft calcification was detected when blood compatibility between homograft donor and receiver was not observed, particularly for patients 3 years old or younger. Accelerated homograft fibrocalcification was clearly more often encountered in the very young patients compared with those older than 3 years, but when blood group compatibility was strictly observed the risk for accelerated homograft fibrocalcification was notably diminished.

Further studies on how to safely reduce the impact of immune response in children receiving cryopreserved valved homografts are needed.

\section{References}

1. Ross DN, Somerville J. Correction of pulmonary atresia with a homograft aortic valve. Lancet. 1966;2:521-7.

2. Bando K, Danielson GK, Schaff HV, Mair DD, Julsrud PR, Puga FJ. Outcome of pulmonary and aortic homografts for right ventricular outflow tract reconstruction. J Thorac Cardiovascular Surg. 1995;109: 509-18.

3. Hawkins JA, Bailey WW, Dillon T, Schwartz DC. Midterm results with cryopreserved allograft valved conduits from the right ventricle to the pulmonary arteries. J Thorac Cardiovasc Surg. 1992;104:910-6. 
4. Niwaya K, Knott-Craig CJ, Lane MM, Chandrasekaren K, Overholt ED, Elkins RC. Cryopreserved homograft valves in the pulmonary position: risk analysis for intermediate-term failure. $J$ Thorac Cardiovasc Surg. 1999;117:141-7.

5. Tweddell JS, Pelech AN, Frommelt PC, Mussatto KA, Wyman JD, Fedderly RT, et al. Factors affecting longevity of homograft valves used in right ventricular outflow tract reconstruction for congenital heart disease. Circulation. 2000;102(Suppl III):III130-5.

6. Chan KC, Fyfe DA, McKay CA, Sade RM, Crawford FA. Right ventricular outflow tract reconstruction with cryopreserved homografts in pediatric patients: intermediate-term follow-up with serial echocardiographic assessment. J Am Coll Cardiol. 1994;24:483-9.

7. Schorn K, Yankah AC, Alexi-Meskhishvilli VA, Weng Y, Lange PE, Hetzer R. Risk factors for early degeneration of allografts in pulmonary circulation. Eur J Cardiothorac Surg. 1997;11:62-9.

8. Santini F, Piccin C, Prioli A, Pessotto R, Mazzucco A. Accelerated aortic allograft fibrocalcification after right ventricular outflow tract reconstruction in pediatric patients: report of two cases. Eur J Cardiothorac Surg. 1996;10:290-3.

9. Clarke DR, Campbell DN, Hayward AR, Bishop DA. Degeneration of aortic valve allografts in young recipients. J Thorac Cardiovasc Surg. 1993;105:934-43.

10. Rajani B, Mee RB, Ratcliff NB. Evidence of rejection of homograft cardiac valves in infants. J Thorac Cardiovasc Surg. 1998;115:111-7.

11. Baskett RJ, Ross DB, Nanton MA, Murphy DA. Factors in early failure of cryopreserved homograft pulmonary valves in children: preserved immunogenicity? J Thorac Cardiovasc Surg. 1996;112: 1170-9.

12. Balch CM, Karp RB. Blood group compatibility and aortic valve allotransplantation in man. J Thorac Cardiovasc Surg. 1975;70:256-9.

13. Lupinetti FM, Cobb KC, Kioshocs HC, Thompson SA, Walters KS, Moore KC. Effect of immunological differences on rat aortic valve allograft calcification. J Card Surg. 1992;7:65-70.

14. McNally R, Barwick R, Smith-Morse B, Rhodes P. Actuarial analysis of a uniform and reliable preservation method for viable heart valve allografts. Ann Thorac Surg. 1989;48:583-4.

15. Pacifico AD, Kirklin JW, Blackstone EH. Surgical management of pulmonary stenosis in tetralogy of Fallot. J Thorac Cardiovasc Surg. 1977;74:382-95.

16. McGoon DC, Rastelli GC, Ongley PA. An operation for correction of truncus arteriosus. JAMA. 1968;205:69-73.

17. Rastelli GC, Wallace RB, Ongley PA. Complete repair of transposition of the great arteries with pulmonary stenosis: a review and report of a case corrected using a new surgical technique. Circulation. 1969;39: 83-95.

18. Danielson GK, Tabry IF, Ritter DG, Maloney JD. Successful repair of double-outlet right ventricle, complete atrioventricular canal, and atrioventricular discordance associated with dextrocardia and pulmonary stenosis. J Thorac Cardiovasc Surg. 1978;75:710-7.

19. O'Brien MF, Stafford EG, Gardner MAH, Pohlner PG, McGriffin DC. A comparison of aortic valve replacement with viable cryopreserved and fresh allograft valves, with a note on chromosomal studies. $J$ Thorac Cardiovasc Surg. 1987;94:812-23.

20. Albert JD, Bishop DA, Fullerton DA, Campbell DN, Clarke DR. Conduit reconstruction of the right ventricular outflow tract: lessons learned in a twelve-year experience. J Thorac Cardiovasc Surg. 1993; 106:228-36.

21. Kanter KR, Budde JM, Parks WJ, Tam VKH, Shama S, Williams WH, et al. One hundred pulmonary valve replacements in children after relief of right ventricular outflow tract obstruction. Ann Thorac Surg. 2002;73:1801-7.

22. Stark J, Bull C, Stajevic M, Jothi M, Elliot M, de Leval M. Fate of subpulmonary homograft conduits: determinants of late homograft failure. J Thorac Cardiovasc Surg. 1998;115:506-16.

23. Heinemann MK, Hanley FL, Fenton KN, Jonas RA, Mayer JE, Castaneda AR. Fate of small homografts conduits after early repair of truncus arteriosus. Ann Thorac Surg. 1993;55:1409-12.

24. Dearani JA, Danielson GK, Puga FJ, Puga FJ, Schaff HV, Warnes $\mathrm{CW}$, et al. Late follow-up of 1095 patients undergoing operation for complex congenital heart disease utilizing pulmonary ventricle to pulmonary artery conduits. Ann Thorac Surg. 2003;75:399-411.
25. Shaddy RE, Hawkins JA. Immunology and failure of valved allografts in children. Ann Thorac Surg. 2002;74:1271-5.

26. Shaddy RE, Tani LY, Sturtevant JE, Lambert LM, McCough EC. Effects of homograft blood type and anatomic type of stenosis, regurgitation and calcium in homografts in the pulmonary position. Am J Cardiol. 1992;70:392-3.

27. Hawkins JA, Breinholt JP, Lambert LM, Fuller TC, Profaizer T, McGough EC, et al. Class I and class II anti-HLA antibodies after implantation of cryopreserved allograft material in pediatric patients. J Thorac Cardiovasc Surg. 2000;119:324-30.

28. Ross DB, Hamilton GR, Wright JR, Lee TDG. Letter to the editor. Homograft valve failure in children. J Thorac Cardiovasc Surg. 1999; 117:1044.

29. Shaddy RE, Lambert LM, Fuller TC, Profaizer T, Thompson DD, Baker SI, et al. Prospective randomized trial of azothioprine in cryopreserved valved homografts in children. Ann Thorac Surg. 2001;71: 43-7.

30. Christie GW, Barrat-Boyes BG. Identification of a failure mode of the antibiotic sterilized aortic allograft after 10 years: implications for their long-term survival. J Card Surg. 1991;6:462-7.

\section{Discussion}

Dr John A. Hawkins (Salt Lake City, Utah). Thank you, Dr Christenson. I always enjoy papers that challenge my personally held beliefs, and I would have to say right up front that generally I have felt that $\mathrm{ABO}$ matching probably does not make much difference, and if I had a preference, I would select a pulmonary valve over an aortic valve.

You have looked at 1 of the bigger problems that we face today in congenital cardiac surgery, basically the problem of premature early valve dysfunction and subsequent explanation of allograft valves used in the right ventricular outflow tract.

The problem of $\mathrm{ABO}$ blood group antigen compatibility and its exact role in late allograft dysfunction has really been hotly debated, with a few who feel that it does make a difference and probably plays a central role in late valve deterioration, and then perhaps even more feel that it probably plays no role in late valve allograft failure, as compared with other factors, such as young age, short donor ischemic times, small $\mathrm{Z}$ values, and aortic valve type. Immune factors have been theorized to be important in allograft degeneration but are difficult to prove as definitive factor in late deterioration.

The primary message of this paper was that $\mathrm{ABO}$ blood group antigen incompatibility leads to an increased incidence of valved allograft calcification in children younger than 3 years of age. A secondary finding was that aortic allografts functioned well and perhaps these are not as bad as we think. The central question raised by the study is, Should we be routinely matching ABOcompatible allografts with our patients to extend and improve the durability of these valved allografts? The implications of this paper are that we should, and personally, I'm not quite so sure. I'm not ready to jump on board yet.

I have several questions. First, the authors report a series of 59 patients who underwent valved allograft implantation: 33 had ABO-compatible valves and 26 had ABO-incompatible valves. There were 9 patients who showed evidence of calcification during a 4-year mean follow-up period, but only 6 patients who required valved allograft reoperation during this same time period.

My first question has to do with the authors' emphasis on calcification rather than valved allograft failure as a primary end point and the need for reoperation. So my first question is, Does calcification of a valved allograft really equate with conduit dys- 
function and reoperation, and is there really any difference between the groups with regard to $\mathrm{ABO}$ incompatibility and the need for reoperation rather than calcification?

My second and third questions are sort of linked and basically have to do with making statistical inferences with regards to attributing differences to $\mathrm{ABO}$ incompatibility rather than young age per se. In other words, how many of the 6 reoperations were in the younger age group as compared with the older age group, and with such small numbers of adverse events, namely 6 out of 59 , can one really attribute any differences to $\mathrm{ABO}$ compatibility rather than simply young age? I don't really know the statistics for doing this. And similarly, do the findings necessarily mean that ABO incompatibility leads to valved allograft calcification, or are younger patients simply more likely to calcify a valved allograft than an older patient?

And lastly, can you tell us how these findings from this study have impacted your own practice?

Dr Christenson. Thank you, Dr Hawkins, for your kind and challenging remarks. To answer your question, if calcification necessarily means conduit dysfunction that requires replacement, our data do not really suggest that this is always the case but the rather high number of cases with allograft calcification in our series did eventually lead to conduit or valvular dysfunction requiring reoperation.

But as you may have noted, there are 3 patients with mild to moderate calcification that as yet have not developed any conduit dysfunction, and only time can give us the fate of these conduits, I believe.

Regarding the question of whether reoperations in the younger age group are due to young age rather than $\mathrm{ABO}$ incompatibility, I wanted to point out that 6 of the reoperations in our series occurred in the very young patients, younger than 3 years of age, at the first operation. All of those patients had calcifications and conduit dysfunction and all of them were in the non-iso group.

None of the young patients with ABO compatibility were observed to develop during the follow-up calcifications, neither calcifications nor conduit dysfunction. And this would, to me, suggest that it's rather that blood group incompatibility may trigger calcifications than the age of the patient itself. As a consequence of our findings today, we routinely match $\mathrm{ABO}$, particularly in the young patient group.

And finally, I think to respond to the central question, it seems based on our data that when blood group match is observed, we do indeed gain conduit and valvular durability, particularly in the young patient group, which has been reported in the literature as having a rather high failure rate when this compatibility is not observed.

I think that perhaps we should rethink a little bit, and if we are forced to use aortic homografts in the pulmonary position due to lack of availability of pulmonary homografts, one should think about having a blood type match.

Dr Richard A. Jonas (Boston, Mass). Can you please clarify whether you did echoes on all of these patients?

Dr Christenson. Well, the mean gradient was $15 \mathrm{~mm} \mathrm{Hg}$.

Dr Jonas. For the whole series?

Dr Christenson. Yes.

Dr Jonas. And was there a significant difference between those who had calcification and those who had gradients?
Dr Christenson. It didn't reach significance, but there was a clear trend.

Dr Carlos J. Troconis (Caracas, Venezuela). In our country, we don't have easy access to homografts and the cost is too high. We have been using xenografts for the past 10 years, using whatever is available to us, mainly from Brazil or recently from Shelhigh, Inc.

In reviewing the world literature several years ago, we found that almost all the homografts by age 4 to 7 years will be calcified or disrupted. So we started to use the xenograft, and in early experiences, we used some low doses of Imuran.

My questions are, Do you think that some type of immunosuppression will improve the outcomes of the grafts? Also, do you think that modifications in the cryopreservation or some gene expression changes will provide more durability in those conduits?

Dr Christenson. Thank you for your question. I do think that with immunosuppressive therapy in these patients, one has to be very careful, because that has a lot of negative implications and risks. A paper described administering immunosuppression, and it did not change the immunological response much, when you looked at the HLA antigen. So that question is not really clear to me, whether one should suggest immunosuppression in these patients. I think if one can stick to the blood group matching, one has already gained quite a lot of terrain.

Dr James L. Monro (Southampton, United Kingdom). I enjoyed that paper, and I think you are right, we should start taking more notice of the blood groups. I find it difficult enough to get hold of homografts anyway. It is now going to be even more difficult.

The point I would like to make is on the method of preparation of homografts. Everything is cryopreserved these days, and they may be fresh, and I think that exacerbates the calcification formation and the degeneration of the valve. But for years I have been using aortic homografts in a small series of infants with truncus arteriosus having aortic homografts; we reported about 3 years ago the mean time to replacement of the homografts was 13 years, and the longest patient we had was 26 years.

Now, I'm sure it is something to do with the fact that we used antibiotic sterilization and then just put them in the fridge for up to 10 weeks at $4{ }^{\circ} \mathrm{C}$ and used them. These were definitely dead valves, and I think they have done much better than the cryopreserved valves that we have these days. I wondered if anybody else is still using that, and whether you think that's the reason these valves seem to have done better.

I was very depressed with the figures that John Brown showed earlier, on how poorly the homografts he was reporting have done. And if you can't get a homograft, the Contegra seems a good idea. But I think the right blood group homograft is still much better.

Dr Jonas. Perhaps that gets to the question as to how well a SynerGraft should function since it is a dead homograft without living endothelial cells. Presumably the SynerGraft should function much better, but I'm not sure that that's the experience I have been hearing. I don't know if anybody would like to comment very briefly, or if you would like to comment on that.

Dr Christenson. I don't really ....

Dr Jonas. Thank you.

Dr Jashari Ramadan (Brussels, Belgium). I think the majority of implanting surgeons agree that the antigenic characteristics of 
the homograft are very low because of the effect of cryopreservation, and that is one of the reasons that the majority of surgeons today agree that neither immunosuppression nor blood group matching is necessary.

My question is actually, Don't you think that the reason for accelerated calcification of the homograft in your group of patients is rather lower age and accelerated growth than the blood group mismatching?

Dr Christenson. Well, of course in relatively small material like this, it is difficult to draw a firm conclusion on this point. I do believe, though, that the calcifications, if we look into the conduit itself, if you have viable cells somewhere in this conduit, it is in the tube itself rather than on the leaflets of the valve, and that's why you see the calcification and retraction. I do believe that we have active cells still in the homografts.

Dr Antonio F. Corno (Lausanne, Switzerland). Very quick question. We noted from Dr Carpentier that homografts implanted at a younger age do calcify much earlier than in older patients because of the accelerated calcium metabolism, and this is further accelerated if the surgeon or the intensivist are using general administration of intravenous calcium in the immediate postoperative care. So the question is, How do you manage the postoperative care in younger patients? Are you using intravenous calcium or not?

Dr Christenson. No, we are not using it at all.

Dr David B. Ross (Edmonton, Alberta, Canada). Just a comment about Jim Monro's remark a moment ago, and another comment about use of reoperation as an insensitive index of homograft failure. In a paper we reported a few years ago, we showed that short storage times prior to cryopreservation actually did influence early failure, but you can't tease that out by using reoperation. We had to use very sensitive and reproducible echocardiographic measurements of valve gradients and regurgitation to ascertain that. We have a paper in press now showing that HLA-DR mismatch also predicts early failure, if you look carefully with echocardiography.

\section{Authoritative}

The Journal of Thoracic and Cardiovascular Surgery is the most frequently cited thoracic/cardiovascular surgery journal in the Science Citation Index. An article in JTCVS is cited on average almost twice as often as those in the closest cardiothoracic journal. 